\title{
Computing program realignments: issues and recommendations
}

\author{
Pankaj Chaudhary, North Carolina Agricultural and Technical State University, pchaudhary@ncat.edu \\ David Smith, Indiana University of Pennsylvania, dtsmith@iup.edu \\ Azad Ali,azadali@comcast.net
}

\begin{abstract}
This paper discusses the issues related to alignment of computing related programs within different colleges and departments. Such alignments are result of institutional formation and market demands of the past, however in recent years may be driven by the student enrollment number challenges. This was the case for a university located in Western Pennsylvania that had three computing related programs in Information technology (IT), Information Systems (IS) and Computer Science (CS). The university decided to realign these three programs through the restructuring of the departments that housed them. The paper discusses the ramification of the decisions from point of view of professional identity of the discipline and the programs. Based on these ramifications it proposes an alternative structure.
\end{abstract}

Keywords: academic identity, computing programs, academic organizational structure

\section{Introduction}

The increasing use of computing technologies in teaching various fields of study has led to various approaches to teaching courses in computing. Computing courses referred to in this manuscript refer to courses in Computer Science (CS), Information Systems (IS) and Information Technology (IT) fields/programs/areas/disciplines. These three fields of computing share a sizeable portion of curriculum and as a result many courses may look similar. However, in reality, these courses may cover different content and/or may employ different pedagogy depending upon the computing field. Outside these computing disciplines different faculty use computer applications as part of their courses and over a period of time may gain substantial experience from using these applications that gives the notion that they can teach computing courses.

The points noted above may prove to be counterproductive for computing programs. It may give the impression that faculty in one computing area (such as faculty in CS) can readily teach courses in other areas like IT and IS. Second, it may give the impression that faculty in other departments with computer application expertise may be able to teach computing courses due to their gained knowledge and expertise from using computer applications in their own courses. Such notions often make their way up the chain to the top university administration who, due to lack of understanding about the nuances of the differences between the computing disciplines, can form an impression that courses and faculty between different computing areas are interchangeable and may assume duplication of resources especially when faced with enrollment challenges. This may lead to the unfortunate restructuring of computing disciplines in a suboptimal fashion. At times of enrollment downturn, administrators may think that computing faculty are easily replaceable (Brown, 2012, Haley, 2013). They may think that computing courses can be taught by faculty from other departments outside the computing areas either because of their experience working with computer applications and because of the topic similarity in computing courses. This was the case for a university in Western Pennsylvania. The university was facing steady enrollment decline for the past three 


\section{Issues in Information Systems}

Volume 22, Issue 4, pp. 269-283, 2021

to four years. The pandemic combined with changing regional demographics dealt a severe blow to the enrollments. To address this downturn, the university elected to move the IS and IT programs, which had been taught by an information systems department in the college of business, to accounting department and CS respectively, with accounting delivering the IS courses including courses shared between IS and IT programs, and CS delivering the courses unique to IT program. In addition, the CS program was previously moved and merged with the mathematics department.

This paper offers suggestions for alternative plan that may address the enrollment downturn and challenges for the three computing programs. The remainder of this study is divided into the following sections:

- First, the study explains the decision that was made by the university which led to the realignment of the computing departments. It also explains the underlying assumptions for making this decision.

- Second, it explains about the professional identity of the students in different computing areas as majors and as professionals.

- Third, a discussion of the standard curriculum is introduced to explain the similarities and differences between the computing programs.

- Fourth, it presents data on enrollment trends for IS, IT and CS programs.

- Fifth, it presents an alternative to address enrollment challenges that takes into account academic identity and curriculum standards.

- Sixth and last, summary, recommendations, and proposed future work are presented.

\section{Current Landscape, the Decision, and the Underlying Assumptions}

Universities around the country are facing the challenge of declining enrollments. For the university of interest contributing to this were two additional factors. First a mandate from the University System to meet certain faculty to student ratio numbers which were based on year 2015, when the enrollment in the whole system was the highest. The steady decline in enrollment in combination with the pandemic meant that these goals were not based on realistic scenarios. Second, western PA high school demographics has been on decline for several years and the university primarily serves western PA region. Even so, the university's mission remains, that is to provide quality affordable education to students in western PA.

In recent years, a decision was made to streamline the IS and IT programs to achieve cost savings and to potentially pare down faculty lines over time. These programs have been taught out of the information systems department. The IT program was introduced in 2018 to prepare the students for the world of cloud computing and data centers and was targeted towards students who were wary of programming which is often part of CS programs. Extensive research was conducted, and the skill set of the existing subset of faculty in the IS program was identified as possessing the requisite skills to teach the curriculum. As of 2020, IS and IT programs has around 100 majors. In addition, the faculty offer a number of service courses in the UG programs, business programs, and the Master's and Ph.D. programs in area of IS and Decision Sciences (DS).

CS curriculum was taught by the department of Computer Science prior to the summer of 2019. At that time to resolve administrative issues, the department was merged with the department of Mathematics to form a new department - Department of Mathematics and Computer Sciences (MACS). Prior to the merger mathematics department was already one of the larger departments in the university with 26 faculty. The mathematics department primarily is a service department providing mathematics courses for programs across the university. While the mathematics department has programs including mathematics education and graduate programs, the total number of majors enrolled was around 100 . The computer science department with 9 faculty primarily offered courses for computer science majors and minors, and a few service courses. The number of majors in the CS department was on the rise with more than 300 majors. After the merger there was movement of mathematics faculty to teach CS courses. Though mathematics 


\section{Issues in Information Systems}

Volume 22, Issue 4, pp. 269-283, 2021

and CS are closely related, there are only a limited number of faculty who may satisfy the content and pedagogical requirements of CS courses.

Given the organizational landscape as described above and to address the enrollment challenges the university made the decision to fold the information systems department and move the IS program to accounting and the IT program to CS.

\section{Underlying assumptions}

The rationalization for the decision was not offered and communicated with the departments involved. Thus, it is presumed that the decision was based on the following underlying assumptions:

- Students can move between departments with minimal impact on the quality of their academic experience and that departments can be aligned seamlessly without significantly affecting students.

- Courses in the IT, IS, and CS are interchangeable and such faculty in each department can readily deliver any of IT, IS and CS courses. Furthermore, faculty from departments such as Accounting, some of whom may have computer application experience, can readily deliver several IT and IS courses.

- Planned mergers and alignments of the departments and programs will address enrollment downturn issues and challenges.

\section{Connecting Underlying Assumptions with Key Studies}

In this study we first address the underlying assumptions with respect to key studies in literature. With respect to the first assumption that students can move amongst departments with minimal impact, we present several studies connected to academic and professional identity. For the second assumption, that courses are interchangeable, we discuss them from the point view of standard curriculum recommendation from recognized academic bodies like Association for Computing Machinery (ACM) and Association for Information Systems (AIS). For the last assumption regarding enrollment, we are going to discuss them from the point view of market demand and different computer jobs. Figure 1 below shows for each assumption, listed in the first row, the point of view from which the assumption can be addressed, shown on the second row.
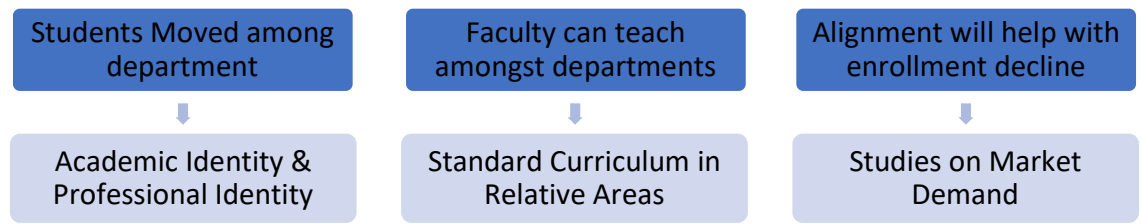

Figure 1 - Underlying Assumptions and Connections to Studies

\section{Academic and Professional Identities}

This section explains the effect of splitting and merging of departments on the formation of the academic and professional identity in the students. The term that is of immediate focus when talking about the identity of the students is the academic identity. However, to fully understand academic integrity, we first need to understand professional identity in general and from the specific view of IS, IT, and CS professionals. Professional identity is what students form upon graduation as they continue to practice in their profession. Therefore, we first begin by explaining about professional identity, then the academic identity and later the professional identity of computing professionals. Last the section discusses the underlying assumption of the university decision which is that the decision to split and merge the computing programs with other departments will have no effect on the students. 


\section{Issues in Information Systems}

Volume 22, Issue 4, pp. 269-283, 2021

\section{Professional Identity}

Literature presents some different definitions of professional identity. Some describe them from person's sense of self while others include morals and feelings in the formation of professional identity. Table 1 below provides three main definitions of professional identity.

Table 1 - Definitions of Professional Identity

\begin{tabular}{|l|l|}
\hline \multicolumn{1}{|c|}{ Source } & \multicolumn{1}{c|}{ Definition } \\
\hline Slay \& Smith, 2011 & $\begin{array}{l}\text { A professional identity is an individual's image of who they are as a } \\
\text { professional. }\end{array}$ \\
\hline $\begin{array}{l}\text { Jensen \& Jetten (2016) } \\
\text { (p. 1027) }\end{array}$ & $\begin{array}{l}\text { Formation of an attitude of personal responsibility regarding one's role in } \\
\text { the profession, a commitment to behave ethically and morally and the } \\
\text { development of feelings of pride for the profession. }\end{array}$ \\
\hline $\begin{array}{l}\text { Lieff et al. (2012) } \\
\text { (p.20 e208) }\end{array}$ & $\begin{array}{l}\text { Professional identity encompasses how individuals understand themselves, } \\
\text { interpret experiences, present themselves, wish to be perceived, and are } \\
\text { recognized by the broader professional community. }\end{array}$ \\
\hline
\end{tabular}

Looking at the definitions listed above, we can identify a few patterns that influence the formation of professional identity. These include responsibilities, values, ethical and moral standards/dimensions, and personal and social dimensions. However, Lieff et al. (2012) were more specific about identifying what contributes into professional identity. They identified the following five factors:

- Understand themselves.

- Interpret experiences.

- Present themselves.

- Wish to be perceived.

- Recognized by the broader professional community.

Identity of certain professions can be recognized more easily than other professions. For example, nursing professionals can be identified readily through the uniform they wear and the same applies to the law enforcement and armed forces professionals. Apart from the physical appearance aspect, medical professionals identify professionally in areas such as the way they understand themselves, have similar understanding of experiences, how they present themselves similarly, and how they talk about common topics to their professional counterparts.

The point that may best describe professional identity is that it is a group of "like-minded people" or a group that understands their conversations more than others. The vocabulary of their conversations tends to be similar than it is from other groups. Their topics of interest could be similar and even the jargons of their conversations tend to be similar. They can relate to what they deal with and what they discuss. This is in contrast to dealing with people who do not have the same professional identity (Hussey \& CampbellMeier (2016). In the latter case, the dealing lacks the same interest, the same vocabulary and the same jargons that is typically discussed among people with the same professional identity. It is obvious that a strong professional identity may lead to career success. Wilson et al. (2016) found that individuals with a strong professional identity are likely to be committed to their careers and make investments in them, which should lead to their success.

\section{Academic Identity}

Considering professional identity of computing practitioners, a pertinent question arises: what does it mean when one mentions academic identity and how different from the professional identity? Quigley (2011) 


\section{Issues in Information Systems}

Volume 22, Issue 4, pp. 269-283, 2021

approached this question from various points. Although no definite and specific answers to the questions were found in the article, Quigley outlined a few factors that can noted when taking about academic identity, these are summarized below:

- Academic identity lacks precisions in terms of description; therefore, it cannot be clearly described in few sentences or in a paragraph.

- The notion of academic identity is formed through constantly shifting topic on how students understand academics.

- It all depends on understanding the commonalities that contribute to forming this identity.

The commonalities noted in the last point above are the points of interest that are formed in students because of their study of similar content and eventually practiced by the students till graduation. So, it is the core to the formation of the "like-minded people" which is essential in the formation of professional identity. So, students who aspire to be in one profession, experience more belonging as they associate with others who aspire to be in a profession that is similar to theirs (Henkel, 2005). Thus, formation of academic identity through coursework that is similar in content and pedagogy is a key element to formation of professional identity later. For example, students in the medical school feel more comfortable talking about topics related to diseases and patients because it belongs to what they study and what they aspire to be in the future, and it is part of their academic identity. Students in the medical field will not have the same belonging when they engage in discussions with students from civil engineering. The same can be said about other professions. Thus, academic identity in most cases will lay the roots to the formation of professional identity.

The function of the academic identity can take on additional importance. This has been described as giving the student a feeling of belonging to a greater academic community, along with an individual experience of personal academic worth that ensures personal visibility in the academic environment. An underdeveloped academic identity can lead to negative consequences, such as low academic achievement, low goal orientation, high stress levels, and low self-confidence about skills and preparedness for future job demands. Furthermore, this can lead to a poorly developed professional identity (Caza \& Creary, 2016, Mancini et al., 2015, Parker, 2017).

\section{Identity of Computing Profession}

The professional identity of computing practitioners and professionals is not so easily identified or distinguished. In order to understand what it means for computing professionals; it will be helpful to first define profession. Quigley (2011) explained that it is an occupation in which members do similar work. We take this a step further and explain it that people in the same profession talk about their work and communicate among the practitioners of the occupation in a way that others do not do thereby holding strongly similar or same professional identity.

All computing professionals (IS, IT, and CS) have commonalities amongst themselves. They study and work around computer technology field. Thus, it will distinguish them from others when their main conversations are about computer technology field. However, the computer technology or computing as a field of study has grown and diversified in ways such that there are now several distinct yet related areas like application development, network administration, system administration, etc. This kind of diversification leads to similar though different professional and academic identities that would be evident in the three programs of IT, IS and CS. IT and IS coverage focuses more on organizational computing needs (Parker, 2018). IS and IT disciplines focus more on issues and topics that are pertinent to the application of technology to solve every-day organizational needs as opposed to CS which may be more focused on innovation and solving intricate problems using the theoretical underpinnings of computer science discipline. The focus in CS is mostly on the technological aspects and theory on developing applications. 


\section{Issues in Information Systems}

Volume 22, Issue 4, pp. 269-283, 2021

IS and IT professionals take the technologies developed by the computer scientists and apply it to solve organizational problems. Nevertheless, there are commonalities that bind people in the computing profession more that it binds them with other professions (Parker, 2019).

\section{University Decision and Identities}

Given this discussion, the decision by the university to move the IT program with CS and to move IS with accounting department runs counter to development of the academic identity of the students, and to the subsequent formation of professional identity. The assumption that students can move into a department with two distinct academic identities from one with a distinct academic identity in the computing field is problematic. Moving IT with CS may appear prudent, however given that department housing CS is dominated by math faculty, the move may be a detriment. An even greater impact is the move of IS into accounting. Accounting and IS students do not have factors that are common and that contribute to the formation of academic identity. The vocabulary of accounting and IT students is different: they do not speak alike; they do not think alike, and it will be hard to establish professional communication channels to form relevant academic identity.

\section{The Computing Curriculum}

As mentioned before although the common notion that the three computing programs (CS, IS and IT) are similar and have courses that teach similar content. This notion is only true to a limited extent since at most times courses may have the same name in the three programs but there are clear differences amongst them in terms of topics covered, depth of coverage and in the method of delivery / pedagogy. This section addresses the point that computing courses can be taught interchangeably amongst the three programs- IT, IS, and CS. It further explains that gaining expertise of using computer applications in certain areas or disciplines that are not related to computing does not necessarily qualify the concerned faculty to teach computing related courses. To explain, we reference curriculum documents and guides that are the authority in higher education, followed widely in the computing area, and have been accepted by most computing academicians as standard curricula.

\section{A Brief History}

The attempts to develop standard computing curriculums have been going on for many years. The basic purpose of these curriculum efforts has been to arrive at some standard guidelines for courses to be taught, and topics to be covered across different academic computing departments (Hart, 2006). The embedded reason for this work is the (seemingly) similarities in content for topics covered across the three computing related programs (IT, IS, and CS) (Ekstrom et al., 2006, Hart, 2006).

There are several organizations that work to develop standards for various computing and technology fields, these include Association for Computing Machinery (ACM), the Institute for Electronic, Engineering and Electric (IEEE), the Association of Information Systems (AIS), and the Association of Information Technology Professionals (AITP). These organizations have worked at many levels to develop standard curriculum for the different computer disciplines (Dark, 2006). Each have published number of documents in this regard through years of their work on the standard curriculum, and standard curriculum documents have emerged for each specific field of study. However, there is one overarching document that has been developed which may best provide an overview of the entire computing discipline: "Computing Curricula 2005 The Overview Report" (Shackelford et al. 2005), often referred to as CC2005.

\section{Computing Fields of Study}

CC2005 identifies five computer related fields: Computer Science (CS), Information Systems (IS), Information Technology (IT), Computer Engineering (CE) and Software Engineering (SE); and provides a 


\section{Issues in Information Systems}

Volume 22, Issue 4, pp. 269-283, 2021

concise description for each. These programs can be first distinguished by domain of practice as shown in Figure 2 (below). CE, CS, and SE programs have an emphasis on software issues whereas IT and IS focus on organizational needs.

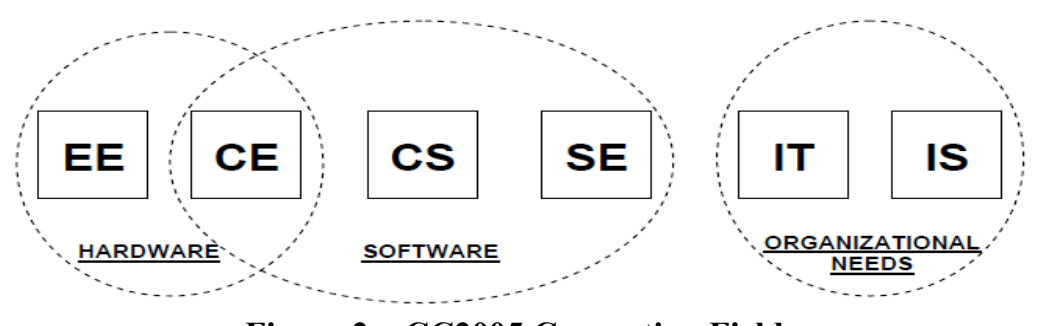

Figure 2 - CC2005 Computing Fields

\section{Computing Fields and Topics}

One of the highlights of CC2005 is the development of a table that compares the weights of topics or content that need to be covered in the each of the fields. A display of this table is shown in Figure 3 below. While the computing fields share a similar, if not the same, list of topics (knowledge areas), the fields are distinguished by the depth at which a given topic is covered. For example, CS programs teach programming at a higher level, thus garnering a suggested minimum coverage of 4 out of 5 points whereas IT and IS program require coverage at a basic level. On the other hand, information systems and analysis of business requirements need to be covered in full depth for IS field of study, marginal depth for IT, and a cursory depth, if any, for CS. This table thus provides valuable insight into a curriculum structure where different fields in the computing area share many courses and yet have other courses that are distinct for a specific field. All programs may use the same introductory computer basics and programming courses. They may also share courses in database fundamentals which may include some theory and practice. Likewise, several other courses may be shared though as stated earlier at different levels of rigor and depth. On the other hand, the CS may include additional distinct courses covering theory of programming languages, further depth in theory of database systems, operating system principles and design, and intelligent systems. IS may have distinct courses on information system development, legal understanding, and e-business. IT may have distinct course on network configuration and management, system integration, and analysis of technical requirements. IT may also have a course on operating systems; however, this course may be distinct from the CS course on operating systems in that the IT course focuses on operating system use and configuration (Computing Curricula Information Technology Volume, 2005). 


\section{Issues in Information Systems}

Volume 22, Issue 4, pp. 269-283, 2021

\begin{tabular}{|c|c|c|c|c|c|c|c|c|c|c|}
\hline \multirow{2}{*}{ Knowledge Area } & \multicolumn{2}{|c|}{$C E$} & \multicolumn{2}{|c|}{ CS } & \multicolumn{2}{|c|}{ IS } & \multicolumn{2}{|c|}{ IT } & \multicolumn{2}{|c|}{ SE } \\
\hline & $\min$ & $\max$ & $\min$ & $\max$ & $\min$ & $\max$ & $\min$ & $\max$ & $\min$ & $\max$ \\
\hline Programming Fundamentals & 4 & 4 & 4 & 5 & 2 & 4 & 2 & 4 & 5 & 5 \\
\hline Integrative Programming & 0 & 2 & 1 & 3 & 2 & 4 & 3 & 5 & 1 & 3 \\
\hline Algorithms and Complexity & 2 & 4 & 4 & 5 & 1 & 2 & 1 & 2 & 3 & 4 \\
\hline Computer Architecture and Organization & 5 & 5 & 2 & 4 & 1 & 2 & 1 & 2 & 2 & 4 \\
\hline Operating Systems Principles \& Design & 2 & 5 & 3 & 5 & 1 & 1 & 1 & 2 & 3 & 4 \\
\hline Operating Systems Configuration \& Use & 2 & 3 & 2 & 4 & 2 & 3 & 3 & 5 & 2 & 4 \\
\hline Net Centric Principles and Design & 1 & 3 & 2 & 4 & 1 & 3 & 3 & 4 & 2 & 4 \\
\hline Net Centric Use and configuration & 1 & 2 & 2 & 3 & 2 & 4 & 4 & 5 & 2 & 3 \\
\hline Platform technologies & 0 & 1 & 0 & 2 & 1 & 3 & 2 & 4 & 0 & 3 \\
\hline Theory of Programming Languages & 1 & 2 & 3 & 5 & 0 & 1 & 0 & 1 & 2 & 4 \\
\hline Human-Computer Interaction & 2 & 5 & 2 & 4 & 2 & 5 & 4 & 5 & 3 & 5 \\
\hline Graphics and Visualization & 1 & 3 & 1 & 5 & 1 & 1 & 0 & 1 & 1 & 3 \\
\hline Intelligent Systems (AI) & 1 & 3 & 2 & 5 & 1 & 1 & 0 & 0 & 0 & 0 \\
\hline Information Management (DB) Theory & 1 & 3 & 2 & 5 & 1 & 3 & 1 & 1 & 2 & 5 \\
\hline Information Management (DB) Practice & 1 & 2 & 1 & 4 & 4 & 5 & 3 & 4 & 1 & 4 \\
\hline Scientific computing (Numerical mthds) & 0 & 2 & 0 & 5 & 0 & 0 & 0 & 0 & 0 & 0 \\
\hline Legal / Professional / Ethics / Society & 2 & 5 & 2 & 4 & 2 & 5 & 2 & 4 & 2 & 5 \\
\hline Information Systems Development & 0 & 2 & 0 & 2 & 5 & 5 & 1 & 3 & 2 & 4 \\
\hline Analysis of Business Requirements & 0 & 1 & 0 & 1 & 5 & 5 & 1 & 2 & 1 & 3 \\
\hline E-business & 0 & 0 & 0 & 0 & 4 & 5 & 1 & 2 & 0 & 3 \\
\hline Analysis of Technical Requirements & 2 & 5 & 2 & 4 & 2 & 4 & 3 & 5 & 3 & 5 \\
\hline Engineering Foundations for SW & 1 & 2 & 1 & 2 & 1 & 1 & 0 & 0 & 2 & 5 \\
\hline Engineering Economics for SW & 1 & 3 & 0 & 1 & 1 & 2 & 0 & 1 & 2 & 3 \\
\hline Software Modeling and Analysis & 1 & 3 & 2 & 3 & 3 & 3 & 1 & 3 & 4 & 5 \\
\hline Software Design & 2 & 4 & 3 & 5 & 1 & 3 & 1 & 2 & 5 & 5 \\
\hline Software Verification and Validation & 1 & 3 & 1 & 2 & 1 & 2 & 1 & 2 & 4 & 5 \\
\hline Software Evolution (maintenance) & 1 & 3 & 1 & 1 & 1 & 2 & 1 & 2 & 2 & 4 \\
\hline Software Process & 1 & 1 & 1 & 2 & 1 & 2 & 1 & 1 & 2 & 5 \\
\hline Software Quality & 1 & 2 & 1 & 2 & 1 & 2 & 1 & 2 & 2 & 4 \\
\hline Comp Systems Engineering & 5 & 5 & 1 & 2 & 0 & 0 & 0 & 0 & 2 & 3 \\
\hline Digital logic & 5 & 5 & 2 & 3 & 1 & 1 & 1 & 1 & 0 & 3 \\
\hline Embedded Systems & 2 & 5 & 0 & 3 & 0 & 0 & 0 & 1 & 0 & 4 \\
\hline Distributed Systems & 3 & 5 & 1 & 3 & 2 & 4 & 1 & 3 & 2 & 4 \\
\hline Security: issues and principles & 2 & 3 & 1 & 4 & 2 & 3 & 1 & 3 & 1 & 3 \\
\hline Security: implementation and mgt & 1 & 2 & 1 & 3 & 1 & 3 & 3 & 5 & 1 & 3 \\
\hline Systems administration & 1 & 2 & 1 & 1 & 1 & 3 & 3 & 5 & 1 & 2 \\
\hline Management of Info Systems Org. & 0 & 0 & 0 & 0 & 3 & 5 & 0 & 0 & 0 & 0 \\
\hline Systems integration & 1 & 4 & 1 & 2 & 1 & 4 & 4 & 5 & 1 & 4 \\
\hline Digital media development & 0 & 2 & 0 & 1 & 1 & 2 & 3 & 5 & 0 & 1 \\
\hline Technical support & 0 & 1 & 0 & 1 & 1 & 3 & 5 & 5 & 0 & 1 \\
\hline
\end{tabular}

Figure 3 - CC2005 Suggested Area of Coverage Across Computing Fields of Study

\section{Re-examining University Decision}

Based on the discussion above, it should be apparent that accounting faculty or in general faculty with application-oriented experience may not be able to effectively teach computing related courses and it applies too in the context of the university being discussed as far as teaching of IS courses is concerned. There are no similarities between the content of the courses that are taught between accounting and IS curriculum. It may also be true that faculty from different departments could have extensive experience in using computer applications for their field but teaching computing related courses is best if left to faculty with expertise in the computing area.

At the same time, it may be more beneficial to have three different distinct faculty sets, each teaching their own field of study. However, this has resource commitments which the universities may not be able to meet in the face of enrollment challenges. Thus, while it is not desirable that computing faculty from the three departments (IT, IS and CS) should teach courses in the different computing disciplines in an interchangeable fashion, if there are resource constraints the next best strategy that is recommended is combining the computing fields under the umbrella of either one department or more appropriately under one college. In such a situation different faculty can teach the core computing component in the needed fashion while at the same time developing limited expertise in other computing discipline for effective use 


\section{Issues in Information Systems}

Volume 22, Issue 4, pp. 269-283, 2021

of resources. This may ensure that faculty may have expert knowledge in one specific field and collectively all fields are covered at an expert level. Team teaching may be resorted to provide required content coverage.

\section{Examination of Enrollment Issues}

In this section, we analyze enrollment demand nationally for IS, IT, and CS programs and we focus on the programs that have high enrollments. We will also discuss the primary underlying assumption from the university decision that the decisions taken will solve the enrollment decline issues.

\section{Existing Enrollment Data}

While it is true that enrollment has declined in the university under consideration in the IS, IT, and even CS programs, the demand for these programs nationally point to a healthy enrollment trend. For example, the CRA Taulbee Survey (Zweben \& Bizot 2019) report points to continuous increase for newly declared $\mathrm{CS}$, and related, majors as shown in Figure 4 below.

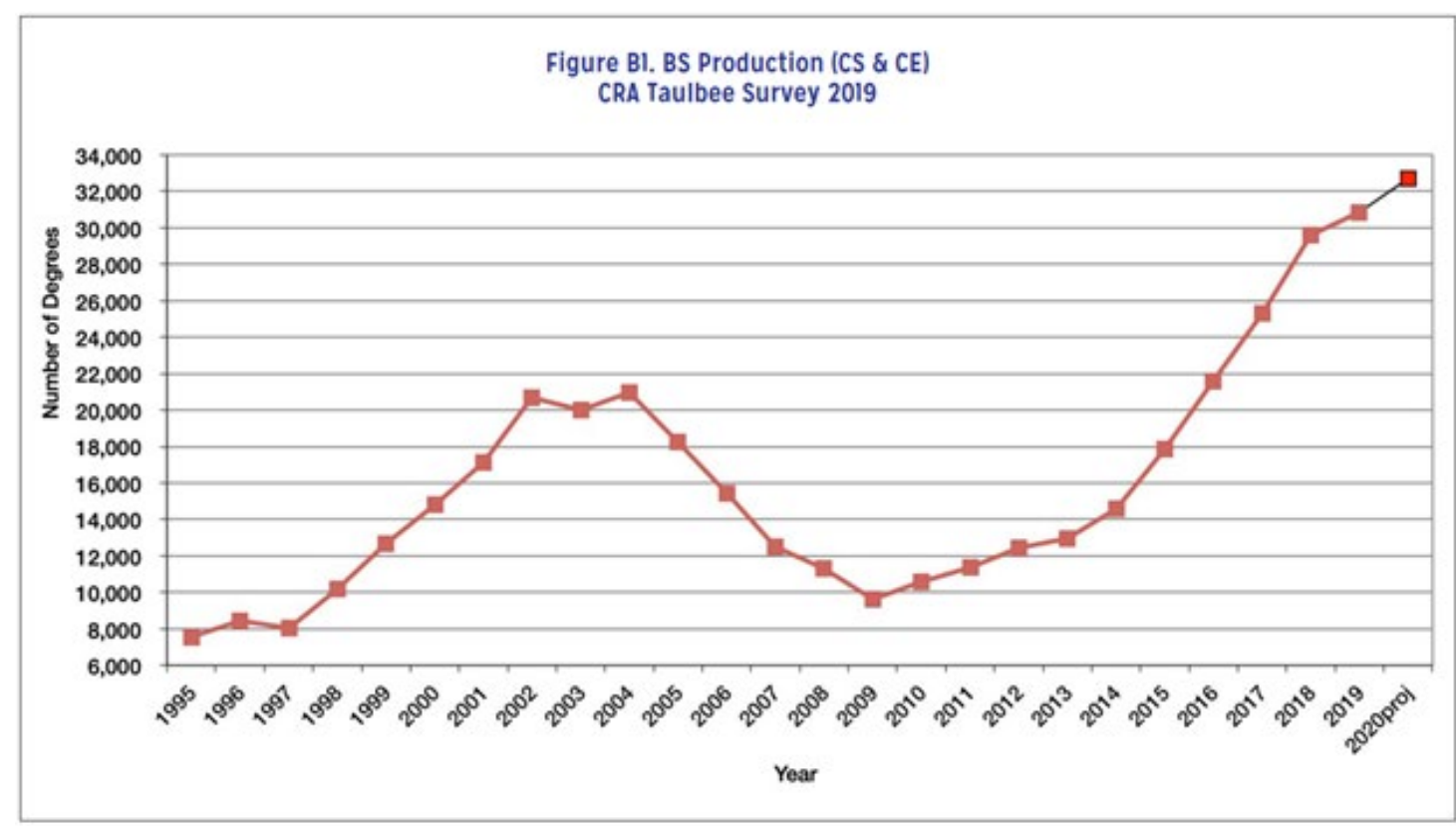

Figure 4 - BS Degree Production in CS and CE (CRA Taulbee Survey)

Data from other sources also show a similar positive trend in enrollment in computing related majors. The pandemic has increased and revived the focus on use of computing technologies to enable work processes in a manner most thought about on a theoretical level. While it is true that not all programs are experiencing positive trend as is the case at the university being discussed. However, it will be helpful to discuss the computing related programs that have high enrollment trends so as to aid in arriving at recommendations at later stages of this manuscript.

\section{Computing Programs in Demand}

Computing area educators often contemplate adding new courses to their curriculum. The rapid changes in technology and the shifting market demand on specific skills add a new dimension to their decision. However, there are points that may need to be considered as guidelines for academic programs struggling 


\section{Issues in Information Systems}

Volume 22, Issue 4, pp. 269-283, 2021

with enrollment decline. Ghannadian (2013) noted that "What Employers Want; What we Teach" in a reference to the influence of market demand on the courses taught. Smith and Ali (2018) were more direct in their recommendations by suggesting that responding to market demand will be key in reversing enrollment downturn. So, the point to understand here is that the best strategy for computing educators is to keep an eye on the market demand, and to develop courses that respond to the market demand. This is a not an easy proposition given how fast the market and the computing industry typically evolves.

In addition to the above, an understanding of the job market demand needs to be supported by current data from reliable data sources. Government data sources are often considered reliable, thus what they publish in terms of trend or outlook for job data can be taken with high degree of confidence. Though at times they may not reflect the latest and greatest, they tend to be company agnostics and devoid of any biases that favors one flavor or technology over others. For instance, the government data focuses on cloud computing as opposed to extolling the virtues of Amazon Web Services (AWS) or Microsoft Azure. The Occupational Outlook Handbook, a research publication that is issued by the U.S. Bureau of Labor Statistics (2021) lists the different occupations that are grouped together by category. A search was conducted on the web site for computing. The search resulted in different categories, the most direct category that relates to the programs being discussed falls under "Computer and Information Technology Occupations". This category of occupations provides ten different occupation titles. Table 2 below lists these together with number of jobs in 2019 and a projected outlook for 2029. Except for the title "Computer Programmers", the outlook is highly favorable with most far exceeding the average job growth of all occupations.

Table 2 - Comparing Employment Numbers 2019-2029 (U.S. Bureau of Labor Statistics 2021).

\begin{tabular}{|l|r|r|r|r|}
\hline \multicolumn{1}{|c|}{ Occupation } & \multicolumn{1}{c|}{$\begin{array}{c}\text { No. Jobs } \\
2019\end{array}$} & $\begin{array}{c}\text { Outlook } \\
2029\end{array}$ & \multicolumn{1}{c|}{ Change } & \multicolumn{1}{c|}{$\begin{array}{c}\text { Percent } \\
\text { Change }\end{array}$} \\
\hline Computer and Information Research Scientists & 32,700 & 37,500 & 5,000 & $15 \%$ \\
\hline Computer Network Architects & 160,100 & 168,100 & 8,000 & $5 \%$ \\
\hline Computer Programmers & 213,900 & 183,800 & $-20,100$ & $-9 \%$ \\
\hline Computer Support Specialists & 882,300 & 959,600 & 67,300 & $8 \%$ \\
\hline Computer Systems Analysts & 632,400 & 679,000 & 46,600 & $7 \%$ \\
\hline Database Administrators & 132,500 & 145,300 & 12,800 & $10 \%$ \\
\hline Information Security Analysts & 131,000 & 171,900 & 40,900 & $31 \%$ \\
\hline Network and Computer Systems Administrators & 373,900 & 389,900 & 16,000 & $4 \%$ \\
\hline Software Developers & $1,469,200$ & $1,785,200$ & 316,000 & $22 \%$ \\
\hline Web Developers and Digital Designers & 174,300 & 188,300 & 14,000 & $8 \%$ \\
\hline
\end{tabular}

Other particular fields of study that are considered to be on high demand are programs that are noted for their STEM designation. STEM in reference to Science, Technology, Engineering and Mathematics. An academic program is considered a "STEM designated" if it is given a CIP code approved by the department of education as a STEM field of study. STEM designated programs are known to attract a substantial number of international students. Graduating from STEM designated program gives international student extension for their Optional Practical Training (OPT) thus substantially increasing their chances of securing employment and the employment Visa that enables them to live and work in the United States. 


\section{Issues in Information Systems}

Volume 22, Issue 4, pp. 269-283, 2021

\section{The Challenge of Programming Courses}

There is often significant attrition of students in the computing programs especially IS and IT on account of programming courses that students are required to take. It has been long agreed on in the computing industry that teaching programming is a must for all computing majors (Bills \& Biles, 2005, Mishra, Cellante \& Kavanaugh, 2014). However, the depth at which programming is taught to students in different computing disciplines is not in total agreement. Advocates of teaching programming point to different advantages that students can gain from having exposure to programming fundamentals and practices. Most recently, there have been calls from different quarters to limit the teaching of programming to different computing majors. This group point to different drawbacks from teaching programming courses. These drawbacks can extend to affect the students and the department that teaches it. The newer move for IT computing discipline is to consider it as a "programming less" major (Bills \& Canosa, 2007). Others most stress the difficulty in learning to program lead to high attrition among students enrolled in computing programs (Daly, 2011).

The favorable news about what is noted here, is that technological advances have created a lot of room for new courses that often do not require learning to program computer languages. With the advent of scripting languages like Python students can still learn the philosophy of programming and logic while avoiding the puritan approach and intricacies of some programming languages. The recent development in the area of low-code and no-code platforms is further taking the customization of applications, user-interfaces, and workflows to everyday users. Technological advances have created massive number of computing fields that can be taught and that has a robust job market in the industry. Some of these fields include cloud computing, virtualization, IT security and many others. Being successful in such fields still requires a strong conceptual foundation in the computing concepts.

\section{Currency of Curriculum}

The key factor as mentioned previously to meet the enrollment challenges is to meet the demands of the job market. When student see a congruence in the curriculum and industry trends their propensity to enroll in the computing program tends to increase along with the ability of the program to market itself. However, this means regular curriculum updates and regular upskilling of the faculty which is not an easy task and at most times a tall order given the time commitments of the faculty in academia in general. Computing as a field of study is rapidly changing and academic departments need to keep updating their programs to keep up with the new development in this field. This is a critical piece of information that university administrators and managers need to be aware of. As a result, they should provide the necessary support to computing departments and faculty with resources to experiment, learn, and engage in professional development. Failure to keep the curriculum updated negatively impact the computing programs in many ways. It gives the impression that the computing program or discipline is behind in the most crucial tool in learning - technology.

\section{University Decision and Curriculum}

It is unlikely that the decision of the university to realign the computing disciplines though a combination of splitting and merging would be sufficient to meet the enrollment challenges. The university needs to capitalize on the renewed focus on computing on account of the pandemic and come up with a cohesive strategy of investing resources and capitalize on the importance of computing in today's business and society in general. The current decision does not address factors that will improve enrollments. It does not include needed updates, modifications, and resources commitments. Given the nature of computing and technology all decisions and plans need to be forward looking. Moving a program IT program that CC2205 designates as business focused and moving it to the CS department violates the core focus of the program. At the same time assuming the IS program is better served in the accounting department may not be seen 


\section{Issues in Information Systems}

Volume 22, Issue 4, pp. 269-283, 2021

as forward looking. The computing programs would be better served by positioning enrollment challenges as an impetus for further curriculum development and improvement and encouraging faculty to upskill.

\section{Recommendations and a Suggested Plan of Action}

The recommendations presented are based on a holistic consideration of academic identity, professional identity, nature of computing disciplines, enrollment challenges, and of course the resource and budget constraints that all the universities are facing. The solution presented is of a reasonable compromise and based on the accumulated experiences of the faculty in conjunction with the consultation with the advisory boards of the different computing departments. The proposed plan is also more also is more consistent with the curriculum planning and is expected to draw back more students and deal with the enrollment decline issue.

\section{Centralized Computing Department}

Bases on the arguments presented so far it is recommended that all three computing programs to be placed under one department. Given the current conditions such a solution is most likely to help address many of the issues that have overwhelmed these computing programs especially the enrollment issues. Combining the three programs into one department will help in the following:

- It will eliminate a limited number of redundant courses between the programs thereby making more efficient use of resources. It may also provide students more clarity in terms of the different courses having the same content.

- Provides students with more options and pathways to design their degrees and program of study. This can be achieved through a core of courses and several tracks. Another option could be a set of core courses plus a suggested set of controlled electives that allow students to gain and build an expertise profile in a certain domain, for example in the area of cloud computing.

- It will eliminate some confusion for students given the programs would be based and run out of the same department rather than different departments in different colleges. Students may be able to transition better between different programs and integrated advising strategies from knowledgeable advisors will help students better decide on a program most appropriate for them based on their capabilities and desired career paths.

- Better collaboration amongst the faculty from the different computing disciplines in the area of teaching, research, grant making, and professional service. The current setup has faculty split between different colleges and departments which does not lend itself to natural collaboration.

- Better strategic, tactical, and operational focus of the computing department under conditions of all offerings of the department being focused on computing. Such focus currently is not achievable with CS and IT being combined with the Math department with higher number of faculty, and IS being part of the accounting department with accounting having higher number of faculty and pursuing an independent AASCB accounting accreditation.

\section{Program Updates: Currency and Relevancy}

The manuscript has previous discussions on the need for the curriculum to be kept updated and in tune with the industry. In this section some specific examples and strategies are offered to keep the program current and more attractive to the students. As noted earlier, IT security is an area of study / computing discipline, that is in demand. The current cybersecurity track in the CS program requires a set of programming courses that may be an overkill for students who may want to primarily want to work in the prevention and detection area or the filed rather than in the forensic analysis area. Program updates to alleviate these pain points for students will lead to better enrollments and a curriculum that is more in tune with some of the more prevalent job descriptions in the market. The issue of taking introductory programming courses and how 


\section{Issues in Information Systems}

Volume 22, Issue 4, pp. 269-283, 2021

negatively they affect enrollment and retention has been addressed in numerous studies. All studies point to the fact that students have difficulty with first programming course and this is a contributing factor that leads to attrition. Making this kind of program modification will likely draw more students into this program.

From a marketing perspective the computing disciplines have courses that have not gone through administrative update cycle though the content has been continuously updated to stay current. Updating the official titles, course catalog, student learning objectives, etc. may serve better at marketing through official updates.

There are several tweaking and continuous improvement initiatives that may be undertaken within a department housing all computing related disciplines and populated with like-minded faculty for whom computing is a passion and their professional identity is more aligned the department as compared to a case where the IS faculty resides in the accounting department.

There are several tweaking and continuous improvement initiatives that may be undertaken within a department housing all computing related disciplines and populated with like-minded faculty for whom computing is a passion and their professional identity is more aligned the department as compared to a case where the IS faculty resides in the accounting department.

\section{Conclusion and Future Work}

Various departments in various universities are facing enrollment challenges that were compounded by the pandemic. The departments and the universities are looking at ways to make the best use of limited resources while maintaining programs. This manuscript touched on a case of one university and realignment of its computing programs. The concepts of academic and professional identity were introduced and were used in conjunction with the standard curriculum recommendations from professional academic organizations to come up with a recommendation that may be better suited to the situation than the proposed realignment. The same concepts may be used by other disciplines to restructure and realign their offerings to better serve the students and meet the enrollment challenges.

The idea of combining all computing programs under the same department and/or perhaps the same college has been experimented with before however there is no peer reviewed literature on what the critical success factors are in making such initiatives successful. The arguments forwarded in the manuscript may be the sufficient conditions though not the necessary conditions to make such solutions work and more work may be needed to come up with the critical success factors to run such departments. This would be an interested area of future work. Equally important area of future research may be where such initiatives were undertaken but were not successful.

Overall, the expectation is that arguments forwarded in this research will help in a more rational realignment of computing programs where such a realignment is necessitated. At the same time, it should be kept in mind that there are several universities where computing programs exist in different departments and are thriving and prospering. The main drivers for realignment may be looked a primarily from the viewpoint of sustainability and growth and if that is achievable then programs should be allowed to continue on the current path so that they can form their independent and strong academic and professional identities.

As of the time of this publication the recommendation of a single department for IS, IT, and CS programs has been presented to administration and the final outcome is yet to be determined. It is our intent to publish a further study next year on the path taken and the net effects on enrollment. Additionally, we intend to broaden our study to provide a survey of the different organization structures housing IS, IT, CS, and other computing programs of a representative sample of universities and gather data / analysis on their success. 


\section{Issues in Information Systems}

Volume 22, Issue 4, pp. 269-283, 2021

\section{References}

Ali, A., \& Shubra, C. (2010). Efforts to reverse the trend of enrollment decline in computer science programs. Issues in Informing Science and Information Technology, 7, 209-224.

Bills, D. P. \& Canosa, R. L. (2007). Sharing introductory programming curriculum across disciplines. Proceedings of the 8th ACM SIGITE conference on Information technology education, 99-106.

Bills, D. P., \& Biles, J. A. (2005, October). The role of programming in IT. In Proceedings of the 6th conference on Information technology education (pp. 43-49).

Brown, A. W. (2012). Cautionary Tales: Strategy Lessons from Struggling Colleges, Stylus Publishing.

Caza, B. B., \& Creary, S. (2016). The construction of professional identity. In Perspectives on contemporary professional work. Edward Elgar Publishing.

Computing Curricula Information Technology Volume (2005). Retrieved March 4, 2007 from ACM Digital Library http://www.sigite.org/

Dark, M. J., Ekstrom J. J., \& Lunt B. B. (2006). Integrating Information Assurance and Security into IT Education: A look at the model curriculum and emerging practice. Journal of Information Technology Education, 5, 389-403.

Daly, T. (2011, May). Minimizing to Maximize: An Initial Attempt at Teaching Introductory Programming Using Alice. Journal of Computer Science in Colleges, 26(5), 23-30.

Ekstrom, J. J., Gorka, S., Kamali, R., Lawson, E., Lunt, B. M., Miller, J., \& Reichgelt, H. (2006). The Information Technology Model Curriculum. Journal of Information Technology Education: Research, 5(1), 343-361.

Ghannadian, F. F. (2013). What employers want, what we teach. BizEd, 12(2), 40-44.

Haley, K. J. (2013). Book Review of, Cautionary Tales: Strategy Lessons from Struggling Colleges by Alice W. Brown and Contributors. The Review of Higher Education, 36(4), 557-559.

Hart, M. (2006). The information technology model curriculum. Journal of Information Technology Education, 5, 337-342. Retrieved from http://jite.org/documents/Vol5/v5p337-342Hart.pdf

Henkel, M. (2005). Academic identity and autonomy in a changing policy environment. Higher Education, 49(1-2), 155-176.

Hussey, L. K., \& Campbell-Meier, J. (2016). Developing professional identity in LIS? Education for Information, 32(4), 343-357.

Jensen, D. H., \& Jetten, J. (2016). The importance of developing students' academic and professional identities in higher education. Journal of College Student Development, 57(8), 1027-1042.

Lieff, S., Baker, L., Mori, B., Egan-Lee, E., Chin, K., \& Reeves, S. (2012). Who am I? Key influences on the formation of academic identity within a faculty development program. Medical Teacher, 34(3), 208-215.

Mancini, T., Caricati, L., Panari, C., \& Tonarelli, A. (2015). Personal and social aspects of professional identity.: An extension of Marcia's identity status model applied to a sample of university students. Journal of Vocational Behavior, 89, 140-150. 


\section{Issues in Information Systems}

Volume 22, Issue 4, pp. 269-283, 2021

Mishra, S., Cellante, D. L., \& Kavanaugh, L. (2014). Why Are Students Running Away From the Computing Major? An Exploratory Study. Issues in Information Systems, 15(1).

Parker, R. (2017, August). Studying Professional Identity in Software Engineering. In Proceedings of the 2017 ACM Conference on International Computing Education Research (pp. 283-284).

Parker, R. (2018, October). Who I am becoming, now: Toward a computer science professional identity instrument. In 2018 IEEE Frontiers in Education Conference (FIE) (pp. 1-9). IEEE.

Parker, R. J. (2019). Developing Software Engineers: Investigating the Influence of a Computer Science Capstone on Professional Identity Formation. ProQuest LLC, Ph.D. Dissertation, University of Colorado at Boulder.

Quigley, S. A. (2011). Academic Identity: A Modern Perspective. Educate , 11(1), 20-30.

Shackelford, R., Cross II, J. H., Davies, G., Impagliazzo, J., Kamali, R., LeBlanc, R., Lunt, B. McGettrick, A., Sloan, R., \& Topi, H. (2005), Computing Curricula 2005 The Overview Report. ACM.

Slay, H. and Smith, D.A. (2011). Professional identity construction: Using narrative to understand the negotiation of professional and stigmatized cultural identities. Human Relations, 64, 85-107

Smith, D. T., \& Ali, A. I. (2018). A welcomed reversal in computer science enrollments: Analysis of contributing factors and recommendations to sustain the growth. Online Journal of Applied Knowledge Management, 6(1), 119-137.

U.S. Bureau of Labor Statistics (2021). Occupational Outlook Handbook: Computer and Information Technology, bls.gov, https://www.bls.gov/ooh/computer-and-information-technology/home.htm

Wilson, M. E., Liddell, D. L., Hirschy, A. S., \& Pasquesi, K. (2016). Professional identity, career commitment, and career entrenchment of midlevel student affairs professionals. Journal of College Student Development, 57(5), 557-572.

Zweben, S., \& Bizot, B., (2019). Taulbee Survey Total Undergrad CS Enrollment Rises Again, but with Fewer New Majors; Doctoral Degree Production Recovers From Last Year's Dip, Computing Research Association. 